\title{
Semi-dwarf narrow rolled leaf mutant in rice: Photosynthetic efficiency and physiological response to gibberellic acid $\left(\mathrm{GA}_{3}\right)$
}

\author{
S. Ramchander $^{*}$ and M. Arumugam Pillai ${ }^{2}$ \\ ${ }^{1}$ Department of Rice (CPBG), Tamil Nadu Agricultural University, Coimbatore-641003 (Tamil Nadu), INDIA \\ ${ }^{2}$ Department of Plant Breeding and Genetics, Agricultural College and Research Institute, Killikulkam-628252 \\ (Tamil Nadu), INDIA. \\ *Corresponding author. E-mail: rubulochander_009@yahoo.co.in
}

Received: July 24, 2015; Revised received: May 10, 2016; Accepted: July 21, 2016

\begin{abstract}
Leaf is the major component for fixation of carbondioxide to produce more photoassimilates and maintains source sink relationship in plants. The present investigation was carried out to study the photosynthetic efficiency and physiological response of $\mathrm{GA}_{3}$ of semi-dwraf narrow rolled leaf mutant. Semi-dwarf narrow rolled leaf mutant exhibited reduced plant height, reduced leaf width, reduced panicle length and number of grains per panicle when compared to wild type. Photosynthetic efficiency study revealed that the mutant showed higher photosynthetic efficiency than wild type. Complementation test with $\mathrm{GA}_{3}$ clearly revealed that this mutant is sensitive to $\mathrm{GA}_{3}$ and revert to normal plant height. Scanning Electron Microscope study revealed that mutant had exhibited minimum number of inter-veins between veins, minimum distance between midrib and has slightly larger cell size. Hence, this loss of function mutant is very useful to map the regions associated with panicle length, number of grains per panicle and other traits related to enhancement of yield. The result provides an important clue for further understanding the mechanism of rice leaf development and plant architecture.
\end{abstract}

Keywords: Gibberellic acid, Photosynthetic efficiency, Scanning electron microscope, Semi-dwarf

\section{INTRODUCTION}

Rice (Oryza sativa L.) being a model plant species for most of the monocotyledons and investigation of their leaf morphology such as size and shape are major determinants of plant architecture and strongly affect high-yield performance. However, leaf morphology, as well as other yield-related components, is a highly complex trait. In rice, many quantitative trait loci (QTLs) controlling such traits have been identified and QTLs for the size of leaves were found to be colocated with sink-related traits (Cui et al., 2003). Leaf is the main factor for photosynthesis and its morphology is closely related to the photosynthetic efficiency and consequently contributing to the yield formation. Recently, there is a report that combination of heterosis untilization with plant ideotype is the only way to achieve higher yield (Yuan, 1997). The morphology of rice leaf is one of the major components of the ideotype in rice. And being appropriate curled can be useful for maintaining the rice leaf upright and helping the population to receive more light (Lv et al., 1991; Su et al., 2003). Because of the importance of leaf shape and size in constructing ideotype in rice, many scientists have put efforts in dissecting the genetic mechanism underlying rice leaf formation by analyzing the leaf shape mutants (Zuo and Li, 2014). To date, a few genes involved in regulating the development of leaf shape, especially the curled leaf shape, have been cloned and functionally analyzed. SLL1/RL9, a member of the KANADI family, encodes a transcription factor (Yan et al., 2008; Zhang et al., 2009), and its mutation leads to the failure of programmed cell death of abaxial mesophyll cells and the suppression of the differentiation of the abaxial cells, and finally to generate adaxially rolled leaves.

Studies of leaf-shape development mainly focus on leaf rolling and size. Several rolled-leaf genes have been cloned and some breakthroughs in this regard have been achieved in rice recently (Zou et al., 2011). However, few narrow-leaf traits have been studied because of the lack of functional deficiency mutants. At present, only seven narrow-leaf mutants are reported to be controlled by a single gene (nal1, nal2, nal3, nal4, nal5, nal6 and nal7), of which Nal1 and Nal7 have been isolated but the molecular mechanisms are still unclear (wang et al., 2009). Creation and identification of novel narrow leaf mutants are important in order to isolate regulatory genes by a map-based cloning strategy and to further understand the mechanisms of rice leaf-shape development. In the present study, the semi-dwarf narrow rolled leaf mutant derived from the mega variety White Ponni via gamma irradiation was used as material to study the photosynthetic efficiency, leaf morphology using scanning electron microscope (SEM) and was also observed for the physioISSN : 0974-9411 (Print), 2231-5209 (Online) All Rights Reserved @ Applied and Natural Science Foundation www.jans.ansfoundation.org 
logical response to gibberellic acid $\left(\mathrm{GA}_{3}\right)$.

\section{MATERIALS AND METHODS}

Plant materials: Biological material used in the present study was semi-dwarf narrow rolled leaf mutant identified in $\mathbf{M}_{2}$ generation using gamma radiation. The $\mathrm{M}_{2}$ seeds of the mutant were forwarded to $\mathrm{M}_{3}$ generation where leaf morphology, vein patterening in leaves, cell pattern in nodal and internodal regions under scanning electron microscope, photosynthetic efficiency of the mutant using chlorophyll fluorometer and $\mathrm{GA}_{3}$ response were studied along with the wild type White Ponni.

Study on Photochemical efficiency (Chlorophyll Fluorometer) : Photochemical efficiency of semidwarf narrow leaf mutant and wild type were recorded by using the handy and portable photochemical efficiency analyser or chlorophyll fluorometer (Model OS30p). Simple fluorescence measurements can be made by the pre-darkening of the leaf sites followed by a short exposure to a saturating light intensity. Measuring the fluorescence intensities over time produces a Kautsky induction curve. The shape of this curve can be used as an indication of environmental stress damage on the photosynthetic apparatus. Measured parameters include $\mathrm{Fo}, \mathrm{Ft}, \mathrm{Fv}, \mathrm{Fm}$ and $\mathrm{Fv} / \mathrm{Fm}$ and OJIP. Photochemical efficiency of the genotype was calculated by the formula given below.

Photochemical efficiency $=\mathrm{Fv} / \mathrm{Fm}$

Where,

$\mathrm{Fv}=$ Variable fluorescence

$\mathrm{Fm}=$ Maximum fluorescence

Study of $\mathrm{GA}_{3}$ response in mutants: Seeds of the mutant was selected in $\mathrm{M}_{3}$ generation were surface sterilized with 2 per cent $\mathrm{HgCl}_{2}$ (Mercuric chloride) solution for 30 minutes and then washed with sterile water. They were placed in wet filter paper and then kept in dark at $30^{\circ} \mathrm{C}$ for two days for germination. Elongation of shoot was quantified by microdrop method (Mitsunaga et al., 1994). After germination, ten uniformly germinated seeds were placed on 1 per cent agar plate and allowed to grow at $25^{\circ} \mathrm{C}$ under fluorescent light till the emergence of second leaf sheath. After two days, $1 \mu \mathrm{l}$ of $\mathrm{GA}_{3}$ solution $(10 \mathrm{mg} / \mathrm{ml})$ was applied to coleoptile region of rice seedlings. Five days after this treatment, the length of the second-leaf sheath was measured and an average of five seedlings was taken to calculate $\mathrm{GA}_{3}$ response (GAR) by the following formula. This $\mathrm{GA}_{3}$ response study was conducted in three replicates under in vitro condition.

$$
\begin{aligned}
& \text { Mean length of second leaf sheath in } \\
& \mathrm{GA}_{3} \text { treatment }
\end{aligned}
$$

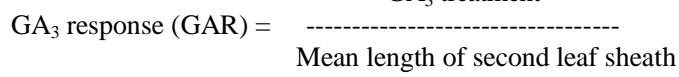

$$
\begin{aligned}
& \text { in control }
\end{aligned}
$$

Scanning electron microscope (SEM): Transverse sections of leaf, nodal region and internodal regions of the semi-dwarf narrow rolled leaf mutant and control were studied for their difference in internal cell arrangement patterns under Scanning Electron Microscope (SEM) (Model : FEI quenta 200 SEM ) built in the Department of Nano Science and Technology, Tamil Nadu Agricultural University, Coimbatore, Tamil Nadu.

\section{RESULTS AND DISCUSSION}

Leaf rolling is an important agronomic trait in rice breeding and moderate leaf rolling maintains the erectness of leaves and minimizes shadowing between leaves, leading to improved photosynthetic efficiency and grain yields. The present investigation identified a unique mutant with some defects in their leaf morphology and plant architecture (Fig 1). This mutant exhibited narrow rolled leaves and reduced height when compared to White Ponni wild type. Rolling leaf material of rice were also helpful in the research of genes related with leaf growth and development as same as regulation mechanisms to osmotic stress (Hsiao et al., 1984). Rolling leaf is easily distinguished from other leaf type. As marker gene rolling leaf characterizer are widely applied in rice genetic and physical mapping research (Shi et al., 2007; Wu et al., 2010), abundance rolling leaf materials in rice which the genetic mechanisms were different have been identified ( $\mathrm{Hu}$ et al., 2010; Luo et al., 2007). Determination of photochemical efficiency of narrow rolled leaf mutants during the peak vegetative phase using photosynthetic efficiency analyzer (Portable chlorophyll fluorometer - Model: OS30p). This study clearly revealed that, semi-dwarf narrow rolled leaf mutants of White Ponni exhibited higher value of photosynthetic efficiency when compared to wild type (Table 1). Most of the rolling leaf mutant increased the colony yield which depends on the decrease yield of single plant. However, the paradox was found that in some research, the net photosynthesis rate of single plant was higher in rolling rice than that of wild-type (Chen et al., 2005). Wang et al. (2012) indicated that rolling leaf mutant decrease the efficiency of light utilization compared to the wild type. This was because of the reduction of leaf area
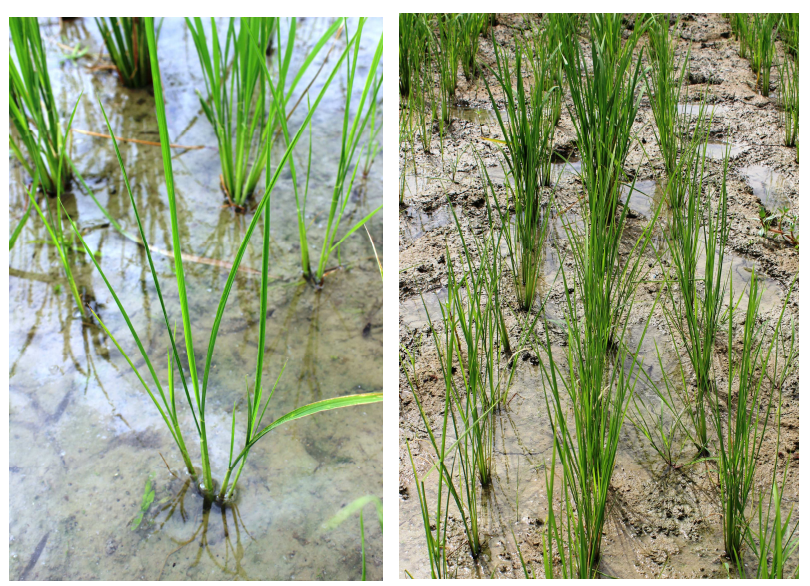

Fig 1. Semi-dwarf narrow rolled leaf mutant of White Ponni. 

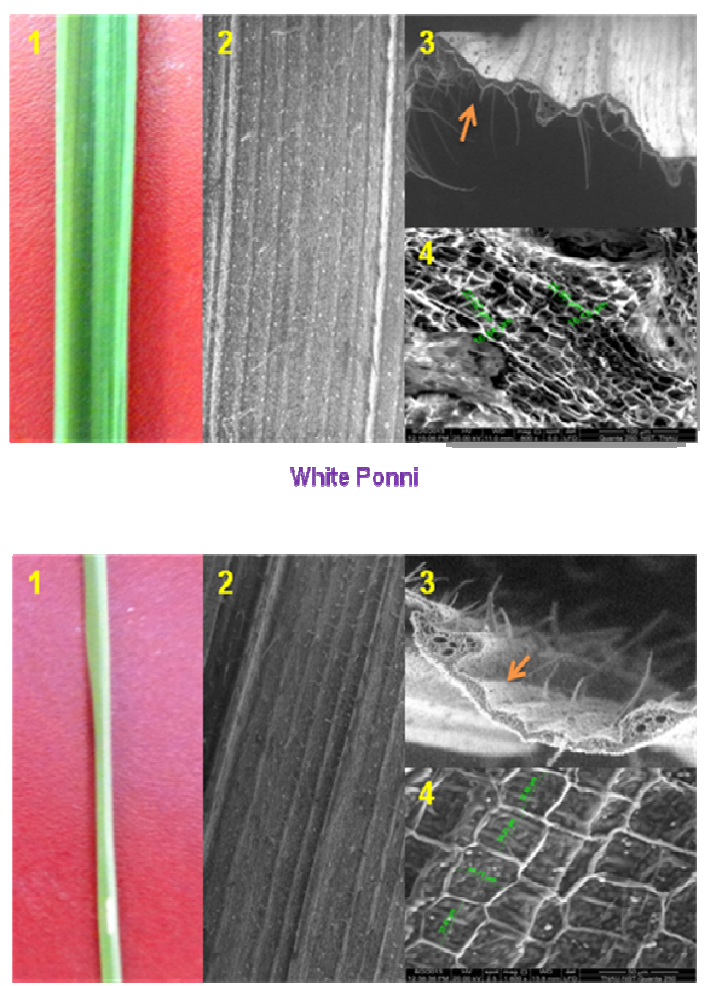

Seml-dwarf narrow rolled leaf mutant of White Ponnl

Fig 2. Variation in leaf morphology and cell structural pattern of third internodal region in white ponni and semi-dwarf narrow rolled leaf mutant. 1. Leaf morphology variation, 2. Vein pattern variation, 3. Intervein variation and 4. Cell pattern variation.

and chlorophyll contents and the dissipation of more excitation energy as non-photochemical quenching as a result of avoiding potential damage of membrane structure. These narrow rolled leaf mutants also exhibited semi-dwarfness, less panicle length and reduced number of filled grains per panicle but their grains was slender when compared to grains of wild type. This may be due to lack of source sink relationship. Thus, the study of rolled leaf mutant will be meaningful for

Table 1. Photosynthetic efficiency of sem-dwarf narrow rolled leaf mutant of White Ponni.

\begin{tabular}{ll}
\hline \multicolumn{1}{c}{ Mutants } & Fv/Fm \\
\hline Semi-dwarf narrow rolled & 0.7107 \\
leaf mutant & 0.6902 \\
White Ponni (wild type) & \\
\hline
\end{tabular}

breeding crops with improved photosynthetic efficiency and subsequently higher yield (Lang et al., 2004).

$\mathrm{GA}_{3}$ response of semi-dwarf narrow rolled leaf mutant of White Ponni was estimated using microdrop method of $\mathrm{GA}_{3}$ application to the coleoptiles region of the seeds three days after germination. Narrow rolled leaf mutant recorded low response to $\mathrm{GA}_{3}$ application (Table 2) (Tanaka et al., 2000). Hence from the study it is better to understand that the muatnt is more sensitive to $\mathrm{GA}_{3}$ application. The complementation test with gibberellic acid exhibited that the identified mutant reverts to its normal plant height when $\mathrm{GA}_{3}$ applied externally. Neeraja et al. (2009) reported that, occurrence of DGWG allele of $s d 1$ gene and GA3 response were analyzed together, existence of two kinds of dwarfs was noticed viz., dwarf accessions with DGWG allele and dwarf accessions without DGWG allele of $s d l$ allele exhibiting varying responses to GA3. Sdl gene with varying response to GA3 could be used as excellent alternate sources for DGWG allele of $s d l$ gene.

In addition to this, the leaf of narrow rolled leaf mutant had exhibited minimum number of inter-veins between veins, minimum distance between midrib and has slightly larger cell size and minimum cell number unit area (Fig 2). These results of our study were supported by the findings of Qi et al. (2008) in a classic rice dwarf mutant named narrow leaf1 (nal1) with affected vein patterning and polar auxin transport. Fujino et al. (2008) reported that, in narrow and curled leaf mutant, mutation resulted in reduced leaf width, no significant morphological changes at the cellular level in leaves were observed. The same study was conducted by Feng et al. (2012) who reported that, the mutant displayed narrow and upper-albino leaf blades with significantly decreased photosynthetic pigment contents throughout their development and narrow leaf trait is caused by a decreased number of small veins.

Lee et al. (2011) also reported that, the mutant leaves had fewer veins and smaller bulliform cells comparing to those of Koshihikari. Mutant had fewer large veins (lateral veins) and small veins (intermediate veins) than those of Koshihikari, resulting in the narrow-leaf phenotypes. Cross-section analysis of mutant leaves showed reduced bulliform cells and exists specifically in the upper side of leaves in rice, and their number and density affects determination of the leaf rolling

Table 2. $\mathrm{GA}_{3}$ response of Semi-dwarf narrow rolled leaf mutant of White Ponni using microdrop method.

\begin{tabular}{|c|c|c|c|c|c|c|}
\hline \multirow{3}{*}{ Mutant } & \multicolumn{2}{|l|}{$\mathbf{G A}_{3}$ non treated } & \multicolumn{2}{|l|}{$\mathbf{G A}_{3}$ treated } & \multicolumn{2}{|c|}{$\mathbf{G A}_{3}$ response } \\
\hline & 5 DAT & 15 DAT & 5 DAT & 15 DAT & 5 DAT & 15 DAT \\
\hline & $\begin{array}{l}\text { Length of } 2^{\text {nd }} \\
\text { leaf sheath }(\mathrm{cm})\end{array}$ & $\begin{array}{l}\text { Length of } 2^{\text {nd }} \\
\text { leaf sheath }(\mathrm{cm})\end{array}$ & $\begin{array}{l}\text { Length of } 2^{\text {nd }} \\
\text { leaf sheath }(\mathrm{cm})\end{array}$ & $\begin{array}{l}\text { Length of } 2^{\text {nd }} \\
\text { leaf sheath }(\mathrm{cm})\end{array}$ & & \\
\hline $\begin{array}{l}\text { Semi-dwarf narrow } \\
\text { rolled leaf mutant }\end{array}$ & 1.90 & 2.77 & 2.78 & 3.75 & 146.32 & 135.54 \\
\hline $\begin{array}{l}\text { White Ponni (wild } \\
\text { type) }\end{array}$ & 1.07 & 2.17 & 1.78 & 3.46 & 166.88 & 159.69 \\
\hline
\end{tabular}


and stretching movement (Li et al., 1979). Therefore, developmental defects of veins and bulliform cells affected the leaf rolling morphology. It has been shown that under drought conditions, bulliform cells lose turgor pressure and shrink, leading to the rolling up of leaves. Once water is sufficient, the bulliform cells expand and the leaves open again (Price et al., 1997; Alvarez et al., 2008). However, the molecular and genetic mechanisms of leaf rolling and the function of bulliform cells in leaf rolling remain to be elucidated. Therefore the elucidation of the genetic basis of the control of leaf shape and size could be of use in the manipulation of crop traits, leading to more stable and increased crop production.

\section{Conclusion}

One of the most important targets to improve crop yield is leaf photosynthetic capacity. The leaf morphology, particularly in crop, is one of the most important agronomic traits because it influences the yield through the manipulation of photosynthetic capacity and transpiration. A new rolling leaf rice mutant was identified which showed an apparently straighter longitudinal shape normal transverse rolling characters at all developing stages. This study also found that the net photosynthesis efficiency of single plant was higher in rolling rice than that of wild-type. This mutant also served as loss of function mutant for various yield related traits viz., reduced plant height, reduced leaf width, reduced panicle length and number of grains per panicle. Therefore, further genetic analysis is necessary to map the genes associated with the above mentioned traits in future breeding programmes.

\section{REFERENCES}

Alvarez, J.M., Rocha, J.F. and Machado, S.R. (2008) Bulliform cells in Loudetiopsis chrysothrix (Nees) Conert and Tristachya leiostachya Nees (Poaceae): structure in relation to function. Braz Arch Biol Technol., 51: 113-119.

Chen, Z.X., Chen, H.Q., Shao, Y.J. Zhang, Y.F. and Pan, X.B. (2005). Effect of rolled leaf Rl (t) gene on grain quality in hybrid rice (Oryza sativa). Chin. J. Rice. Sci., 19: 315-318.

Cui, K.H., Peng, S.B., Xing, Y.Z., Yu, S.B and Xu, C.G. (2003). Molecular dissection of the genetic relationships of source, sink and transport tissue with yield traits in rice. Theor Appl Genet., 106:649-658

Feng, W.L., Hao, F.and He, J.Y . (2012). Photosynthetic characterization of a rolled leaf mutant of rice (Oryza sativa L.). Afr. J. Biotechnol., 11(26): 6839-6846.

Fujino, K., Matsuda, Y., Ozawa, K., Nishimura, T., Koshiba, T., Fraaije, M.W. and Sekiguchi, H. (2008). NARROW LEAF 7 controls leaf shape mediated by auxin in rice. Mol. Genet. Genomics., 279: 499-507.

Hsiao, T.C., O'Toole, J.C., Yambao, E.B. and Turner, N.C. (1984). Influence of osmotic adjustment on leaf rolling and tissue death in rice. Plant Physiol., 75: 338-341.

Hu, J., Zhu, L., Zeng, D., Gao, Z., Guo, L., Fang. Y., Zhang, G., Dong, G., Yan, M., Liu, J. and Qian, Q. (2010).
Identification and characterization of NARROW AND ROLLED LEAF 1, a novel gene regulating leaf morphology and plant architecture in rice. Plant Mol. Biol., 73: 283-292.

Lang,Y.Z., Zhang, Z.J., Gu, X.Y., Yang, J.C. and Zhu, Q.S. (2004). Physiological and ecological effects of crimpy leaf character in rice (Oryza sativa L.) II. Photosynthetic character, dry mass production and yield forming. Acta. Agron. Sin., 30: 883-887.

Lee. S, Choi, M., Lee, J. and Koh, H.J. (2011). Characteristics and Genetic Segregation of a Rolled Leaf Mutant in Rice. Kor. J. Breed. Sci. 43(4): 181-185.

Li, Qin-Xiu, Xu-Xian Peng and Yu-Lan Wang, (1979). Widecross between Oryza longistaminata A. Chev. et Rochr. and $O$. sativa L. Sichuan J. Agr. Sci. Tech. 1: 65-66.

Luo, Z., Z. Yang., B. Zhong., Y. Li., R. Xie., F. Zhao., Y. Ling., G. He . 2007. Genetic analysis and fine mapping of a dynamic rolled leaf gene, RL10(t), in rice (Oryza sativa L.). Genome, 50: 811-817.

Lv, C. G., Gu. F.L., Zou, J.S. and Lu, M. L. (1991). Studies on yielding potential and related characterstics of rice ideotype. Sci Agric Sin, 24(5): 15-22. (in Chinese with English abstract).

Mitsunaga S, T. and Tashiro, J. (1994). Yamaguchi Identification and characterization of gibberellin-insensitive mutants selected from among dwarf mutants of rice Theoretical and Applied Genetics, 87(6): 705-712.

Neeraja, C.N., Vemireddy, L.R., Malathi, S. and Siddiq, E.A. (2009). Identification of alternate dwarfing gene sources to widely used Dee-Gee-Woo-Gen allele of $s d l$ gene by molecular and biochemical assays in rice (Oryza sativa L.). Electron. J. Biotechnol.,12. 10.2225/vol12-issue3.

Price. H and Tomos, A. D. (1997) "Genetic Dissection of Root Growth in Rice (Oryza Sativa L.). II: Mapping Quantitative Trait Loci Using Molecular Markers," Theoretical and Applied Genetics, Vol. 95, No. 1-2.

Qi, J., Qian, Q., Bu, Q., Li, S., Chen, Q., Sun, J., Liang, W., Zhou, Y., Chu, C., Li, X., Ren, F., Palme, K., Zhao, B., Chen, J., Chen, M. and Li, C. (2008). Mutation of the Rice Narrow leaf1 Gene, Which Encodes a Novel Protein, Affects Vein Patterning and Polar Auxin Transport. Plant Physiol., 147: 1947-1959.

Shi, Z., Wang, J., Wan, X., Shen, G., Wang, X. and J. Zhang. (2007). Over-expression of rice OsAGO7 gene induces upward curling of the leaf blade that enhanced erect-leaf habit. Planta., 226: 99-108.

Su, Z. F., Xu, N. X., Sun, C. M. and Zhang Y. J. (2003). Study on the relationship between rice plant type indices after heading stage and yield formation. Sci Agric Sin, 36(1): 115-120. (in Chinese with English abstract).

Tanaka, M.U., Fujisawa, Y., Kobayashi, M., Ashikari, M., Iwasaki, Y., Kitano H. and Matsuoka, M. (2000). Rice dwarf mutant $\mathrm{d} 1$, which is defective in the $\alpha$-subunit of the heterotrimeric $\mathrm{G}$ protein, affects gibberellin signal transduction. PNAS, 97: 11648 -11643.

Wang, H., Chen, Z., Guo, T., Liu, Y. and Li, H. (2009). Genetic Analysis and Gene Mapping of Dwarf Mutant Rice CHA-1. Induced Plant Mutations in the Genomics Era. Food and Agriculture Organization of the United Nations, Rome: 431- 433.

Wang, L.F., Hao. F. and Ji, Y.H. (2012). Photosynthetic characterization of a rolled leaf mutant of rice (Oryza sativa L.). Afr. J. Biotechnol., 11(26): 6839-6846. 
S.Ramchander and M.Arumugam Pillai / J. Appl. \& Nat. Sci. 8 (3): 1312 - 1316 (2016)

Wu, C., Fu, Y., Hu, G., Si, H., Cheng, S. and Liu, W. (2010). Isolation and characterization of a rice mutant with narrow and rolled leaves. Planta, 232: 313-324.

Yan, S., Yan, C. J. and Gu, M. H. (2008). Molecular mechanism of leaf development. Hereditas, 30(9): 1127-1135.

Yuan, L. P. (1997). Hybrid rice breeding for super high yield. Hybrid Rice 12: 1-6.

Zhang, G., Chen, L., Xiao, G., Xiao, Y., Chen X. and Zhang, S. (2009). Bulked segregant analysis to detect QTL related to heat tolerance in rice using SSR markers. Agric. Sci. China 8: 482-487.

Zou, L.P., Sun, X.H., Zhang, Z.G., Liu, P., Wu, J.X., Tian, C.J., Qiu, J.L., Lu. T.G. (2011). Leaf rolling controlled by the homeodomain leucine zipper class IV gene Roc5 in rice. Plant Physiol., 156: 1589-1602.

Zuo, J. R. and Li, J. Y. (2014). Molecular dissection of complex agronomic traits of rice: A team effort by Chinese scientists in recent years. Nat Sci Rev, 1: 253-276. 